\title{
A CITATION-BASED TEST FOR DISCRIMINATION AT ECONOMICS AND FINANCE JOURNALS
}

Scott Smart

Joel Waldfogel

Working Paper 5460

\author{
NATIONAL BUREAU OF ECONOMIC RESEARCH \\ 1050 Massachusetts Avenue \\ Cambridge, MA 02138 \\ February 1996
}

We are grateful to Ian Ayres, Steve Berry, Jenny Hunt, Jeff Milyo, Richard Rosen, Anjan Thakor and Joe Tracy for helpful discussion. Thanks to the American Economic Association, CSWEP, and James Hasselback for providing data. Jessica Loomer, Karen Smith, Andrew Spieler and Matthew Stefan provided able research assistance. We are responsible for any errors. This paper is part of NBER's research program in Law and Economics. Any opinions expressed are those of the authors and not those of the National Bureau of Economic Research.

(C) 1996 by Scott Smart and Joel Waldfogel. All rights reserved. Short sections of text, not to exceed two paragraphs, may be quoted without explicit permission provided that full credit, including $\odot$ notice, is given to the source. 
NBER Working Paper 5460

February 1996

\title{
A CITATION-BASED TEST FOR \\ DISCRIMINATION AT ECONOMICS AND \\ FINANCE JOURNALS
}

\begin{abstract}
Discrimination is notoriously difficult to document. Convincing tests for discrimination require good measures of the legitimate determinants of the outcome of interest, for example wages and productivity. While few contexts provide data adequate to the task of measuring discrimination, copious bibliographic data on the impact of academic research make possible tests of discrimination in the editorial process. This study develops a test for possible bias - with respect to author gender, prestige of author's institution, article content (theory vs. empiricism), and whether the author has ties to the editor - using a new approach based on an analysis of citations. We treat citations as a measure of article quality and ask whether papers by certain groups receive systematically different numbers of citations. The key to our approach is the observation that editors do not simply accept or reject papers. For accepted papers, editors determine articles' order within journal issue and length based on their quality assessments. We show that these "editorial treatment" decisions are highly correlated with citations. Thus, we infer bias against a particular group of authors if their published articles have more citations, conditional editorial treatment, than other articles. Surprisingly, we document systematic editorial bias in favor of authors located outside of top institutions.
\end{abstract}

Scott Smart

Department of Finance Indiana University

Bloomington, IN 47405
Joel Waldfogel

Department of Economics

Yale University

New Haven, CT 06520

and NBER 


\section{Introduction}

Discrimination is notoriously difficult to document. The paradigmatic approach, regression of some outcome such as wages or criminal sentences on race, gender, and control variables, is dogged by the problem of omitted variables: the coefficients on race or gender may either reflect discrimination or the correlation between race and gender and unobservable and legitimate determinants of the outcome of interest. Convincing tests for discrimination require good measures of the legitimate determinants of the outcome of interest. For example, one could convincingly measure discrimination in wages, at least in spot markets, if productivity were observed. While few contexts provide data adequate to the task of measuring discrimination, copious bibliographic data on the impact of academic research make possible tests of discrimination in the editorial process.

Researchers have devoted considerable attention to the possibility that the editorial process at academic journals may be biased against women, authors not associated with highstatus institutions and other groups. Most existing studies look for evidence of bias by examining whether manuscript acceptance rates are related to characteristics of authors. A major problem with this approach - analogous to the problem in the traditional approach to measuring wage discrimination - is that acceptance rates may be correlated with author traits, not because of discrimination, but because research quality is also correlated with author characteristics. For example, one would expect the quality of submitted manuscripts from authors affiliated with top-tier universities to be higher on average than the quality of manuscripts submitted by authors at less prestigious institutions, leading to differences in acceptance rates between the two groups of authors. 
Blank (1991) reports the results from an experiment conducted at the American Economic Review (AER) in which submitted manuscripts were randomly assigned for either single-blind or double-blind review. Under a single-blind system, referees know authors' names and institutional affiliations, while this information is withheld under a double-blind system. Referee identities are not disclosed to authors under either system. Presumably double-blind review precludes bias according to author type because referees do not know author identities. Because manuscripts are randomly assigned in the AER experiment, there were no systematic differences in either manuscript or author characteristics across review processes. In the absence of discrimination, the outcomes produced by the single-blind system should be similar to those produced by the double-blind system. ${ }^{1}$ While Blank finds no significant effect of reviewing system on women's acceptance rates, she finds that authors at lower-ranked institutions experience lower acceptance rates under the double-blind system. This is surprising because it shows that authors at lower-ranked institutions fare better when their identities are known to referees. In other words, single-blind refereeing appears to bias the review process in favor of authors outside of top institutions.

This study develops a test for possible bias - with respect to gender, prestige of authors' institution, whether the author is connected to the editor, and by article subject matter - using an entirely different approach based on an analysis of citations. We regard the number of citations articles receive as a measure of the articles' quality. It is common, for example, to use

'Or differences in the outcomes produced by single-blind and double-blind review processes should not be correlated with author characteristics. 
citations data to rank the influence of academic departments, scholars and individual papers. ${ }^{2}$ Leibowitz and Palmer (1984) use citations to rank economics journals and departments. Alexander and Mabry (1994) provide recent citation-based rankings of journals, authors, and articles in financial research. Anecdotal evidence suggests that producing a paper that is widely cited has a more positive impact on promotion and tenure outcomes than producing work, even in top journals, that does not influence the profession. Finally, editors appear to care about the citations that their journals receive. Schwert (1993) reports that Robert Merton persuaded the editorial board at the Journal of Financial Economics to use citations to papers published in the $J F E$ "as one of the major measures by which to evaluate the Journal and its influence on the profession."

One way to test for editorial favoritism is to compare mean citations to published articles by different sorts of authors to determine whether certain groups of authors have systematically different averages. If editors exhibit favoritism towards a particular group by publishing papers of lower quality submitted by the favored group, then these papers should receive lower citations. This is the insight of Laband and Piette (1994), who study whether editors exhibit favoritism towards former students and colleagues.

Yet, a comparison of average citations to published articles will yield meaningful inferences about editorial bias only under very restrictive assumptions. If we view citations as quality and editors as quality screens, the average citations to published papers is the mean, conditional on quality exceeding the threshold for manuscript acceptance. Possible bias (either

\footnotetext{
${ }^{2}$ See section VI below for an examination of whether citations reflect article quality, as opposed to authors' ability to garner citations for other reasons.
} 
favoritism or discrimination) operates through the application of different thresholds to different types of authors. Even in the absence of editorial bias, however, the average citations to published work will be equal for different sorts of authors only if distributions of manuscript quality (for manuscripts above the publication threshold) are identical for the different groups. Thus, differences in mean citations that are systematically related to author characteristics may indicate differences in the quality of papers written by these authors rather than editorial discrimination.

The key to our approach to measuring discrimination is the observation that editors do not simply accept or reject manuscripts. For accepted manuscripts, editors use their expected quality assessments to determine the ensuing article's order (lead article, second, etc.) and page length. ${ }^{3}$ We demonstrate below that these decisions are highly correlated with articles' impacts. Therefore, we can examine articles that a journal's editor expects to have similar quality by grouping them according to order and length. We interpret differences in mean citations within these groups as evidence of bias. We infer bias against a particular group of authors if their published articles have more citations, conditional on order and length, than other articles. Similarly, the editorial process exhibits favoritism towards a group if the group's papers have lower average citations holding editorial treatment constant.

It is important to state at the outset what we mean by "discrimination." Our test cannot

${ }^{3}$ Editors undoubtedly exercise greater control over the order in which an article appears in a given issue than over the length of the article. Even so, editors exercise some control over the length of articles they publish by requiring authors to cut sections that are unnecessarily technical or are of secondary importance to the main point of the article. In the analysis that follows, none of our conclusions are qualitatively altered if we take the view that editors do not exercise control over article length. 
indicate whether editors intentionally treat manuscripts differently according to content or author identity. Rather, our tests simply indicate whether articles' editorial treatment is warranted by their realized quality. Furthermore, even if we find evidence of discrimination, for example against women, our tests cannot unambiguously determine whether the discrimination is caused by gender or some unobserved characteristic correlated with gender. However, unlike most extant empirical studies of discrimination in which productivity is unobserved, our method would allow us to conclude that the editorial treatment of female authors is not warranted by article quality. In that sense, our analysis provides a clean test for the existence of discrimination.

This paper proceeds as follows. First, we compare our subject matter and approach to the existing literature. Second, we describe the data used in this study. Third, we describe our approach for identifying editorial favoritism, and we show evidence of editors' ability to assess manuscript quality ex ante. Fourth, we document systematic editorial bias in favor of authors located outside of top institutions. We find no systematic evidence of bias with respect to author gender and little systematic evidence of bias according to article content. We find that editors at two joumals discriminate against their colleagues but not their former students, while editors at one journal appear to favor authors with Ph.D.s from the institution where the journal was published. Fifth, we address potential concerns that our main result of discrimination against top-20 authors is attributable to problems with our use of citations as a measure of article quality. We present longitudinal evidence demonstrating that there is no significant effect of institutional rank on citations holding article quality fixed. Finally, we compare our results to results from related studies using different approaches. 


\section{Existing Literature}

An existing literature looks for various types of biases in the editorial review process. Garfunkel et al (1994) examine whether institutional prestige as measured by the dollar value of research grants received influences acceptance rates at the Journal of Pediatrics. They find no effect of affiliation on acceptance rates for full-length manuscripts and a positive relationship between prestige and acceptance rates for brief reports. Gilbert, Williams and Lundberg (1994) find no relationship between editor or reviewer gender on publication outcomes for articles submitted to the Journal of the American Medical Association. Several papers draw comparisons between outcomes produced by single-blind versus double-blind review processes to infer bias in the editorial process. Ferber and Teimann (1980) find that manuscripts with female authorship have higher acceptance rates under double-blind procedures while male-authored manuscripts have roughly the same acceptance rates under both procedures. The results suggest a bias against women, but in their comparison across journals, they cannot control for the quality of submitted manuscripts across single- and double-blind joumals. Using a randomized experiment, Blank (1991) finds that female acceptance rates at the AER decrease less than male acceptance rates under double-blind (as opposed to single-blind) procedures, although the differences are not statistically significant. ${ }^{4}$

Peters and Ceci (1980) and Blank examine possible bias against low-status institutions, with different conclusions. Peters and Ceci perform an experiment in which thirteen previously

${ }^{4} B$ lank recognizes that referees can sometimes determine the author of a paper even under a double-blind reviewing system. The data collected in the AER experiment permitted Blank to analyze outcomes for "truly blind" papers, and she reports evidence of favoritism towards authors at lower-ranked schools in this subsample as well. 
published psychology articles were submitted to major psychology journals under false names associated with nonexistent (low status) institutions. Three of the thirteen papers were detected; of the remaining ten, nine were rejected. Their results imply a bias against authors at low-status institutions. Blank (1991) also examines the effect of single-blind reviewing on acceptance rates across authors' institutional ranking. She finds that double-blind reviewing - which is presumably free of bias - has no effect on acceptance rates on manuscripts by authors at top 5 institutions (roughly 29 percent in either regime). Under single-blind refereeing, the AER accepted 20.9 percent of papers by authors at institutions ranked 6-20, while under double-blind refereeing, their acceptance rates were only 13.4 percent. $^{5}$ Similarly, AER acceptance rates for authors at 21-50 institutions were 15.0 and 10.1 percent, respectively, under single and double blind systems. Rather surprisingly, Blank's results imply editorial bias in favor of authors outside of top institutions in the single-blind regime.

In a study that employs a methodology superficially similar to the one we develop below, Laband and Piette (1994) test whether twenty-eight leading economics journals favor authors with ties to the editor by comparing citations across author with and without such connections. ${ }^{6}$ They find that citations are higher for articles written by authors with connections to editors, a result which they interpret as evidence that editors use their professional connections to seek out

${ }^{5}$ Notice that the acceptance rates for authors at top institutions are higher than acceptance rates for authors at lower-ranked institutions under either refereeing system. As noted earlier, this does not constitute evidence of bias against authors from lower-ranked schools.

'Laband and Piette (1994) regress citations on a lead article dummy and measures of article length, author gender, author age, author connections to editor, author's past citations, and joumal quality. Note that Laband and Piette (1994) include articles not chosen by the editor, such as presidential addresses, in their sample. As they indicate in their footnote 3, they include a lead article dummy to control for the possibly differential impact of such articles. 
high-impact papers. However, because their analysis does not condition on editors' expectations of quality, their comparison of mean citations across groups of articles is not informative about editors' minimum quality thresholds for publication.

Testing for discrimination in the editorial process by looking at subsequent citations to accepted papers is analogous to testing for discrimination in mortgage lending by looking at default rates. ${ }^{7}$ Recent work by Ferguson and Peters (1995) demonstrates the difficulty of testing for discrimination by comparing default rates across types of borrowers. Bias arises from applying different thresholds to different groups of borrowers; hence, in a biased system the marginal borrower in a disfavored group has a lower expected default rate, but that does not imply that the mean default rate for all borrowers in the disfavored group will be lower. Consequently, a comparison of mean default rates does not indicate differences in the threshold applied to different groups (i.e., is not a good test for discrimination). If data were available which indicated the loan officer's ex ante assessment of each borrower's probability of default, then one could test for discrimination by determining whether these assessments were systematically biased for a particular group of borrowers. Fortunately, the editorial review process routinely generates information on editors' assessments of article quality (order and pages) which enables us to test for discrimination.

\section{Data}

The data for this paper include citations to articles published in seven major economics

\footnotetext{
${ }^{7}$ Other studies discuss tests for discrimination using outcomes. Ayres and Waldfogel (1994) test for race discrimination in bail setting using rates charged by bail bondsmen. Hellerstein and Neumark (1995) test for discrimination against women in Israeli firms by comparing their pay with estimates of their marginal productivity derived from production function estimates. The availability of excellent information on article quality that can be used as a benchmark for assessing editorial favoritism is unusual. Professional sports is another industry in which extensive statistics on productivity allow measurement of discrimination (see Kahn (1991)).
} 
and finance journals. Included are the American Economic Review (AER), Journal of Political Economy (JPE), Econometrica (ECTA), Quarterly Journal of Economics (QJE), Journal of Finance (JF), Journal of Financial Economics (JFE), and Journal of Financial and Quantitative Analysis (JFQA) for the years 1980 to 1985 . We include citations to these articles that appear in other published articles by 1990 . This allows us to calculate the citations within a minimum of five years for all papers in the sample. Citation data come from the Social Science Citation Index (SSCI), which covers a broad range of academic social science journals. We include citations from all journals indexed in the SSCI.

Because we are testing for bias in editorial treatment, the cited articles in the database include only articles that entered the seven journals through standard refereeing. Hence, we exclude all papers from conference proceedings and symposia. In addition we include only fulllength papers. That is, we exclude all notes, comments, and replies. The sample includes citation data on 1962 articles.

In addition to the citation data, we have information on author characteristics allowing us to test for bias. In particular, we have information on authors' gender, institutional affiliation, and Ph.D. vintage. In addition, we have information about the articles' subject matter and number of authors.

We obtained information on author gender using two sources. For economics authors we use the Committee on the Status of Women in the Economics Profession (CSWEP) membership list. For finance authors we use a list provided by James Hasselback. We obtained the Ph.D. year for authors of more than half of the papers in the sample from the American Economic Association membership directory and most of the rest from Hasselback (1995). We 
obtained institutional affiliation data on the authors of cited papers primarily from the SSCI. Where these were missing, we collected this data from the articles directly.

We rank the economics authors' institutions using the Jones et al (1982) rankings employed in Blank (1991). The finance rankings are from Niemi (1987), who ranks departments based on publications appearing in three top finance journals from 1975-1986.

Three of the seven journals in our sample have fixed associations with academic institutions. For articles in these three journals we also collected data indicating whether an author shares an affiliation with the academic institution where the journal is published. Specifically, for articles published in the JPE, QJE, and JFE we determine whether the author is a faculty member at the time of publication or a former Ph.D. student from Chicago, Harvard, or Rochester, respectively. We refer to these authors as insiders.

Co-authorship complicates the definition of author variables. Following Blank, we classify a paper as female-authored if any authors are female. We assign an institutional rank based on the rank of the highest ranking author. We assign a Ph.D. vintage using the Ph.D. year of the author who received the earliest Ph.D. among authors whose Ph.D. date is available. For the journal-specific tests mentioned in the previous paragraph, we classify an article as being authored by an insider if any author shares an affiliation with the institutional home of the journal. We also create a variable indicating the number of authors on an article.

Supplementing author information is information about the subject of the article. From the American Economic Association's (1995) Econlit database, we obtained four-digit subject codes for each of the articles, which we use to divide articles into theory and empiricism. We 
rely on the first field code reported.

Table 1 reports characteristics of the sample. The average number of citations in the first five years is 14.3 . The articles' average citations vary substantially across journals. For the economics journals the averages vary between 21.3 at the AER to 9.3 at the QJE. For finance journals in the sample the variability is greater. Citations within five years average $\mathbf{2 5 . 2}$ at the JFE and 3.6 at the JFQA.

Roughly one in twenty of the papers is female-authored. Over 20 percent of the papers are authored by individuals at top 5 institutions. Another 27.0 percent are by authors at institutions ranked 6 to 20. Authors at institutions ranked 21 to 50 account for another fifth of the articles, and authors at US academic institutions ranked below 50 account for 12.7 percent of the articles. The remaining articles are authored by individuals outside U.S. academic institutions.

Nearly 60 percent of the articles are classified as theory, although this fraction varies substantially across journals. Nearly 90 percent of articles in ECTA are classified as theory, while only 38 percent of articles in the JFE are classified as theoretical.

Just over half of the articles are written by a single author, 54.5 percent. Fewer than 10 percent of all articles have more than two authors. The author vintage variable is available for 1326 observations. Of these, the average years elapsing between the earliest Ph.D. granted (among coauthors) and article publication is 9.2.

The bottom rows of Table 1 report the fraction of articles published by "insiders" at the

${ }^{8}$ We define codes 0200-0251, 0260-0272, 1110-1132, 1312, 1324, 2110-2119, 2130-2135, $3131,4110-4114,4232,4312,4411,5110$, and 8210 as theoretical articles. We define the remainder as empirical articles. 
JPE, QJE, and JFE. More than 22\% of all papers published in the JPE and QJE from 19801985 are authored or coauthored by scholars with Ph.D. degrees from Chicago and Harvard, respectively. Of course, both Chicago and Harvard have produced many productive researchers, so these figures by no means provide evidence of favoritism. Only about one in ten articles published in these three journals is authored by a faculty member at the journals' home institutions.

\section{Editorial Treatment and Bias}

The goal of this section is to motivate a test for possible bias in the review process based on the relationship between editorial treatment (an ex ante measure of paper quality) and actual citations (ex post quality). $\quad$ The following example illustrates our approach. Suppose there are only two types of manuscripts, high and low quality, that editors can distinguish them perfectly, and that citations reflect quality. In the absence of bias, only high-quality manuscripts are accepted. Any difference in the average number of citations across author types then reflects editorial bias. Now, suppose there are two types of acceptable manuscripts, very high and high quality, which editors publish as lead and second articles, respectively, in two-article joumal issues. If author characteristics are correlated with manuscript type - for example if authors at top institutions are more likely to produce manuscripts of very high quality - then differences in mean citations across author types will not constitute evidence of editorial bias. The test for

\footnotetext{
'We use the term "editorial treatment" to describe the order in which an article appears in an issue of a journal and the number of pages devoted to the article.
} 
bias is, instead, whether there are differences in mean citations, conditional on order. ${ }^{10}$

It is crucial for this analysis that editors be able to assess paper quality. If editors decide on the order and length of papers based on their assessments of manuscript quality, then in the absence of bias, the relationship between editorial treatment and quality, as measured by subsequent citations, is the same for all types of authors and manuscripts. Below we document that measures of editorial treatment are strongly correlated with article quality, and therefore that editors can assess paper quality. This allows us to test for bias by comparing citations to papers by different groups of authors, conditional on editorial treatment. The review process favors a particular group if, conditional on editorial treatment, papers by group members receive fewer citations. Strictly speaking these are tests for bias in editorial treatment rather than publication, per se. However, if the determinants of editorial treatment for published articles are also the determinants of whether manuscripts are accepted for publication, this evidence will be relevant to bias in manuscript acceptance decisions.

Figure 1A shows how average citations within five years varies by article order within journal issue, for articles published in the four economics journals between 1980 and 1985 . Figure 1B contains the same information for the three finance journals in our sample. The figures demonstrate that editors can assess quality. Though the relationship is not monotonic

\footnotetext{
${ }^{10}$ In practice, expected quality distributions may differ across articles by different groups of authors. For example, Borokhovich, et. al (1995) demonstrate that authors at the top 40 institutions account for half of all articles published in the 16 leading finance journals from 1989-1993. By contrast, authors at the top 20 institutions received half of all citations, suggesting that they write more influential papers on average. In our sample, authors at the top 20 institutions account for nearly half the publications. The higher degree of concentration of publications by authors from top schools in our sample is not surprising because we focus our analysis on a narrower set of high-quality journals.
} 
at every journal, citations tend to fall as an article's placement in a journal moves away from the lead article position. The pattern is more pronounced for the first three or four articles per issue, though there is a downward trend even beyond that point that is apparent when all journal articles are pooled. Moreover (although not reported), this downward sloping curve is evident at the 75th, 50th and 25th percentiles in the distribution of citations for each order position. The presence of the article order pattern at various points in the distribution indicates that the mean pattern is not driven by blockbuster papers.

Recall that we exclude from the sample articles, such as Nobel lectures and presidential addresses, not chosen by the editor. The reported patterns in Figures 1A and 1B therefore reflect editors'ability to assess manuscripts. ${ }^{112}$

The first column of Table 2 reports a regression of citations within five years on order and journal dummies. The coefficients on article order dummies show a fairly steady declining pattern. Journal and article order dummies together explain 16.4 percent of the variation in citations. The second column reports estimates from a regression which also includes other

\footnotetext{
${ }^{11}$ Laband and Piette (1994) include Nobel lectures and other non-editor-chosen lead articles in their sample, leading them to include a lead article dummy in their citation regressions to control for such articles' potentially different impact. Note that their rationale for including a lead article dummy - adjusting for the quality of presidential addresses, etc. - is distinct from our use of editorial treatment variables as measures of editorial assessment.

${ }^{12}$ The reader may be concerned that article order determines citations, rather than expected article citations determining article order, as we have hypothesized. To check for this possibility we conduct two tests. There are 11 exogenous lead articles in the sample and therefore 11 articles that are editors' first choices that appear second. First we compare citations to the 11 articles immediately following exogenous lead articles (psuedo-lead articles) with citations to regular lead articles, and we find no statistical difference. Second, we compare citations to the 11 psuedo-lead articles with citations to regular second articles. The psuedo-lead articles, like regular lead articles, receive significantiy more citations than the regular second articles. Hence, there is no evidence that citations are affected by order.
} 
editorial treatment variables such as the page length and its square, and the interaction of order and pages. These variables now explain over 20 percent of the citation variation. The third column uses first and second order terms in article position rather than order dummies, with roughly the same results.

\section{Testing for Biases}

Given that editors can assess manuscript quality, do they assess quality differently for different groups? For our first look at this question, we employ article order as a onedimensional summary of the editorial assessment. No bias implies that articles with the same order will have the same average number of citations, whoever is the author and whatever the subject matter. ${ }^{13}$

Figures 2 through 4, showing how average citations by order vary across author gender, author vintage, and article field, show no clear direction of bias. These figures are calculated from mean regressions of citations within 5 years after publication on journal dummies and the interaction of ten order dummies and various author or article characteristic dummies. Hence, the pattern of citations in order is averaged across journals. The figures show the levels relevant for the AER. Figure 5 shows how average citations by article order vary by the institutional rank of the author. For this figure, author institutions are divided into top 20 and other. This figure shows clear evidence of bias in favor of authors located outside of top 20 institutions. For every article order, articles by authors outside of top 20 departments receive fewer citations.

\footnotetext{
${ }^{13}$ Note that this logic does not apply to the lead article, because editors assign to the lead position articles they expect exceed a some quality threshold. Even in the absence of bias, average citations may differ across groups' lead articles simply because one group's quality distribution has a denser upper tail.
} 
Editors place articles by non-top 20 authors in higher positions than are warranted by subsequent citations.

To test for bias more systematically, we regress citations within five years of publication on editorial treatment variables, journal dummies, and variables for author gender and institutional rank, as well as article field. The gender dummy takes a value of one if the paper has at least one female author. The field dummy takes the value of one if the paper is classified as theory and zero if it is an empirical paper. We also create separate dummies for institutions ranked $6-20,21-50$, and 51 or higher, as well as dummies for nonacademic and foreign institutions. We include a variable for the number of authors. Because of the way we classify multiple-authored articles - for example as female-authored if any authors are female - we separately account for multiple authorship to ensure that our measured gender effect does not reflect multiple authorship. Table 3 reports regression results echoing the results in Figures 2-5. The first two columns report mean regressions. In column (1) we condition on editorial treatment using only order dummies. In column (2) we use first and second-order terms in article order and pages, as well as order*pages. Both columns show very similar coefficients on the bias variables. After accounting for the editorial treatment of the paper, as well as a journal effect, author gender and article subject have no significant effect. However, the author's institutional rank has a large and systematic effect in all three specifications. As institutional rank declines, the average number of citations also declines, after accounting for the editorial assessment. ${ }^{14}$ Column (3) reports results of a median regression using the same

\footnotetext{
${ }^{14}$ We experimented with both article order dummies and first and second order terms in article order, with nearly identical results for the variables of interest. In unreported regressions we included a Ph.D. vintage variable for the subset of papers with available data and found no differences in citations between papers written by authors with different experience levels.
} 
specification as column (1). While magnitudes are smaller (the median of the citation distribution is below the mean), the sign and significance pattern is very similar, showing that the results in the mean regressions are not driven by outliers. A strong implication of Table 3 is that editors favor authors located outside of top institutions.

The number of authors has a positive and significant coefficient $(1.00)$ in the median regression, while the coefficient is only marginally significant in the mean regressions. This result may indicate editorial bias against multiple-author manuscripts. Alternatively - and troubling for our approach, which explicitly treats citations as a measure of quality - this result may reflect multiple authors' ability to generate more publicity. Note, however, that the magnitude of this effect is trivial. Adding two additional authors to a paper results in two additional citations, a much smaller effect than the institutional affiliation relationship documented above. We address concerns about the validity of citations as a measure of quality in Section VI below.

Because each journal has a separate editorial process, the possible biases may differ across journals. Table 4 reports results of a regression in which all variables are interacted with journal dummies. Panel $A$ of the table reports the effects of editorial treatment, while the bottom panel reports the results of interest, the coefficients on bias variables. For parsimony we condition on editorial treatment using only order and its square, interacted with each journal dummy. (Results are substantively the same in unreported regressions also using terms in pages and order*pages as measures of editorial treatment). Some sorts of bias which averaged out in the overall regression appear strong here.

Only two of seven journals have significant bias by article subject matter. The JPE has 
a marginally significant bias against theory (in a two-sided test with 95 percent confidence), while the AER has a similar-sized but insignificant bias against theory. Conditional on editorial treatment, theory articles published in the AER and JPE receive roughly 15 percent more citations. The JFE has a large and significant bias against empiricism: theoretical articles published in the JFE have an average of 10.3 fewer citations within five years than empirical articles. Theory articles at the JF receive 2.6 fewer citations, but the difference is not statistically significant.

The bias in favor of authors located outside of top 20 institutions is large and significant at 5 of 7 journals (all of the economics journals and the JF). The bias is proportionally largest at the AER, where non-top 20 authors have about 10 fewer citations per article on an overall average of about 20 citations. While there are no significant gender effects by journal, femaleauthored articles at the JFE receive 8.4 fewer citations (with a $t$-statistic of -1.35 ), after accounting for editorial treatment.

Finally, Table 5 reports our findings on the possibility of favoritism toward "insiders" at the JPE, QJE, and JFE. Our regression includes the same editorial treatment and bias variables as in Table 4, as well as separate dummy variables that equal one when insiders, faculty or former Ph.D. students, publish articles in the journal which shares their institutional affiliation. The strongest results on insider favoritism are that articles in the JPE and JFE by Chicago and Rochester faculty, respectively, have significantly more citations, after conditioning on editorial treatment. In other words, editors at the JPE and JFE appear to require higher quality of their colleagues' articles for the same editorial treatment. By contrast, JFE articles by Rochester Ph.D.s receive fewer citations, after conditioning on editorial treatment, and the 
difference is marginally significant. Thus, there is weak evidence of editorial favoritism toward Rochester Ph.D.s at the JFE.

Our result that editors at the JPE and JFE apply higher standards to faculty at Chicago and Rochester, respectively, is consistent with Laband and Piette's finding that articles by insiders receive more citations, although the interpretation of our result is different because we condition on editorial treatment variables. ${ }^{15}$ The QJE does not exhibit favoritism towards either Harvard faculty or Ph.D. students.

Coefficients on other bias variables change somewhat with the inclusion of insider variables (as well as the use of a smaller sample with valid insider variables). The coefficients on the non-top-20 dummies for the JPE and QJE become smaller and less significant, and the apparent biases in favor of theory articles and female authors at the JFE becomes stronger.

\section{Do Citations Measure Article Quality?}

The reader may be concerned that citations measure quality inaccurately, in particular that authors at top-ranked institutions receive citations for reasons unrelated to the quality of their papers. If authors outside of top-ranked institutions received fewer citations for any level of article quality, then our results above do not necessarily reflect editorial favoritism.

We can identify five reasons why citations might overestimate quality of articles by authors at top-ranked institutions. First, authors submitting manuscripts may seek favorable reviews by citing journal editors or referees, who tend to be at top-ranked institutions. We term

\footnotetext{
${ }^{15}$ The distinction between the bias we measure with respect to faculty and former students is also consistent with a result that Laband and Piette result describe but do not report (see Laband and Piette (1994), page 201).
} 
this the "flattery effect." Second, and related to the first, referees and editors may encourage authors of submitted articles to cite their work. We call this the "influence effect." Third, authors at top schools are better able to publicize their work, for example through working paper series and the availability of travel budgets. We call this the "publicity effect." Fourth, authors at top institutions may be connected in an informal network that excludes others. Because members of this network tend to publish more and to cite each other's work, articles by authors outside the network may receive fewer citations than are warranted by the articles' true quality. We term this the "club effect." Finally, authors at top institutions teach and advise more Ph.D. students, who later cite the work of their teachers and advisers. We term this the "adviser effect. "

All of these concerns stem from the possibility that authors' institutional rank may affect citations, over and above the effects of quality. The panel nature of data on the annual flow of citations allows us to test whether citations are influenced by authors' institutional rank. We test for pure institutional rank effects on citations by examining citations to articles by authors who switch institutions (and whose institutional ranks may therefore also change). In the absence of switching institutions, the authors' articles would receive some measurable time pattern of citations. We test for a pure institutional rank effect by allowing for a possible shift in the time pattern of citations for switchers.

For this exercise, we restrict attention to the 500 single-authored sample articles published in the four economics journals between 1980 and 1985. We include only economics journals because we obtain employment history information from the AEA membership 
directory, which has poor coverage of finance faculty. We examine the annual citations to these articles between the year of their publication and 1990. Of these articles, 149 are written by individuals who switch institutions between the time their article is published and the date of the last citations in our sample (1990). Of the 149 switchers, 48 move from top 20 institutions to other top 20 institutions, 37 move from top 20 institutions to non-top 20 institutions, 21 move from non-top 20 institutions to top 20 institutions, and the remaining 43 move from non-top 20 institutions to other non-top 20 institutions.

We must account for the time pattern of citations to properly identify institutional rank effects on citations. By including article effects (in a fixed effects regression) we control for article quality as well. In the fixed effects regression, estimated institutional rank effects reflect the effect of the change in authors' institutional rank on citations.

We estimate the following regression:

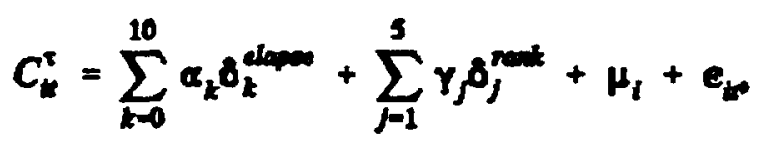

where

$\mathrm{C}_{\mathrm{it}}{ }^{\tau}=$ citations to article $\mathrm{i}$ (published in year $\tau$ ) from articles appearing in year $\mathrm{t}$, $\delta_{k}^{\text {clepsec }}=1$ if $t-\tau=k, 0$ otherwise,

$\delta_{j}^{\text {rak }}$ is a dummy for different institutional ranks $j=1$ for 6 to 20,2 for 21 to 50,3 for $51+, 4$ for nonacademic, and 5 for foreign institutions), $\mu_{\mathrm{i}}=$ article i's unobserved time-constant quality, and $\epsilon_{i \mathfrak{i}}=$ the idiosyncratic unobserved quality component for article $i$ in time $t$. The coefficients $\alpha_{0}$ to $\alpha_{10}$ show the time pattern of citations, and the coefficients $\gamma_{1}$ to $\gamma_{s}$ show the institutional rank effects.

Table 6 reports regression results. The first column shows results of an OLS regression, 
while the second column reports fixed effects results. Both specifications show that time elapsed since publication has a systematic effect on annual citations. Annual citations reach a peak in the sixth year after publication. ${ }^{16}$

Estimated rank effects are starkly different in the two specifications. In the OLS results, which do not control for article quality, articles by authors outside top 20 institutions receive 2 to 3 fewer annual citations than articles by authors at top 20 institutions (and this difference is strongly significant). In the fixed effects results, which control for article quality, however, institutional rank effects are jointly insignificant. ${ }^{17}$ Hence, there is no evidence that rank affects citations, over and above the effect of rank on article quality.

In addition to our panel tests, we performed other tests to address some possible objections to the use of citations as a measure of quality mentioned above. First, to control for the publicity effect, we reestimated our bias regressions using citations in the 3rd to 5th years after publication rather than citations in the 1 st to 5 th years. Some authors at top institutions are able to generate publicity through the circulation of their manuscripts in established working paper series. Because of lags in the publication process, citations in the first two years after

${ }^{16}$ The reader may be concerned that we measure article quality using citations in the five years following publication while the panel evidence indicates that the flow of citations peaks in the sixth year after publication. Regression tests reported above were also run using citations received until 1990 as the dependent variable. (This gives 10 years of citations for articles published in 1980, nine for articles published in 1981, etc.) These regressions also include dummies for publication year. The pattern of results is identical to those reported. This is perhaps not surprising given that the correlation between citations in the first five years and the first ten years, for articles published in 1980, is 0.95 .

${ }^{17}$ This is also true when we summarize rank effects with a non-top 20 dummy. The OLS effect is -2.1 (with a standard error of 0.17 ), while the fixed effects estimate is $-0.50(0.36)$, which is not only not significant at the 95 percent level, but is also less than a quarter percent as large as the OLS estimate. 
publication are likely to reflect the citing author's access to the cited paper prior to publication which, in turn, is more likely if the cited manuscript circulated widely prior to publication. Redefining the dependent variable to exclude citations within two years of publication, we still find the same pattern of favoritism towards authors from non-top 20 schools. Hence, the results do not appear to be driven by top-school authors' ability to generate prepublication publicity. ${ }^{18}$

Second, to control for the flattery, influence, and club effects, we assigned a quality rank to each citing journal based on Leibowitz and Palmer's (1984) impact-adjusted ranking of journals in 1980. We divide citing journals into two groups, major economics and finance journals and others. The list of major journals citing articles in our sample is meant to be overinclusive and includes 67 journals. Two thirds of the citations to the articles in the sample are from these journals. We presume that both authors and referees at the remaining journals are less likely to be associated with major economics or finance programs. If so, then authors submitting manuscripts to these journals do not need to cite top 20 authors to curry favor with potential referees and editors. In fact, we might expect to observe the opposite. Authors submitting manuscripts might cite the work of authors at lower-ranked schools who are editors or referees for lower-tier journals. Because authors are less likely to be part of an elite club of economists, focusing on lower-ranked journals also avoids the club effect mentioned above. Using only citations from non-top economics journals as the dependent variable in the bias regressions, we continue to find the same pattem of favoritism towards authors from non-top 20 schools.

\footnotetext{
${ }^{18}$ It also seems plausible that if citations were driven by publicity, the effect of multiple authorship on citations would be significant and large. Recall our previous finding that adding an additional author to a paper generates only one additional citation.
} 
In the end, we would argue that most of the objections raised against citations as a measure of quality ignore the endogeneity of the characteristics that are alleged to bias citations. Authors at top schools supervise more students, have more exposure to colleagues, etc., because of the quality of their work. Leamer (1981) dismisses many of the concerns raised about citations as a measure of quality as follows:

Many of you will conjure up reasons why the number of citations should be ignored. There are fads; there are self-citations; there are conspiracies; there are derogatory citations; there are bribes to editors and referees; there are sycophantic students; and there are subjects capable of direct understanding only by a few. But why didn't your papers start fads; why don't you publish more and cite yourself; why did your conspiracies fail; why don't you become an editor; why don't your students care about your welfare; and why do you insist on writing about obscure issues?

For readers who remain concerned about whether differences in citations, conditional on editorial treatment, provide evidence of discrimination, we point on that the pattern of discrimination we document in this paper is remarkably similar to the results reported by Blank. Results here provide independent confirmation of Blank's gender results as well as her surprising finding on institutional affiliation. Conditional on editorial treatment, we find no statistically significant difference in citations by gender and hence no evidence of gender bias. In contrast, compared to their expected citation-based merits, manuscripts by non-top authors received treatment more favorable than their eventual citations warrant.

\section{Conclusion}

Discrimination is difficult to document empirically because productivity is typically difficult to observe. Some industries, notably academic research and professional sports, generate information about individuals' productivity in sufficient detail to allow direct 
measurements of bias. In this study we have evaluated the decisions of journal editors against the standard of actual article quality. We find that, as a group, editors in seven economics and finance journals are biased in favor of authors located outside of top 20 institutions. We find no evidence of bias against female authors and little overall evidence of bias by field. Our main results on institutional rank effects are consistent with evidence in Blank's (1991) study of acceptance rates and are quite robust. Furthermore, we test for the possibility of favoritism towards "insiders" at the QJE, JFE and JPE, and find little evidence that authors affiliated with the institutional home of these journals receive better treatment than outsiders. In fact, the opposite is true at the JPE and JFE, at least for faculty insiders. The quality of papers written by Chicago (Rochester) faculty and published in the JPE (JFE) is higher, conditional on editorial treatment, than the quality of JPE papers written by others. Our paper leaves for future research the question of why editors display bias in favor of or against a particular group of authors. 
Figure $1 \mathrm{~A}$

Citations to Econ. Articles by Order

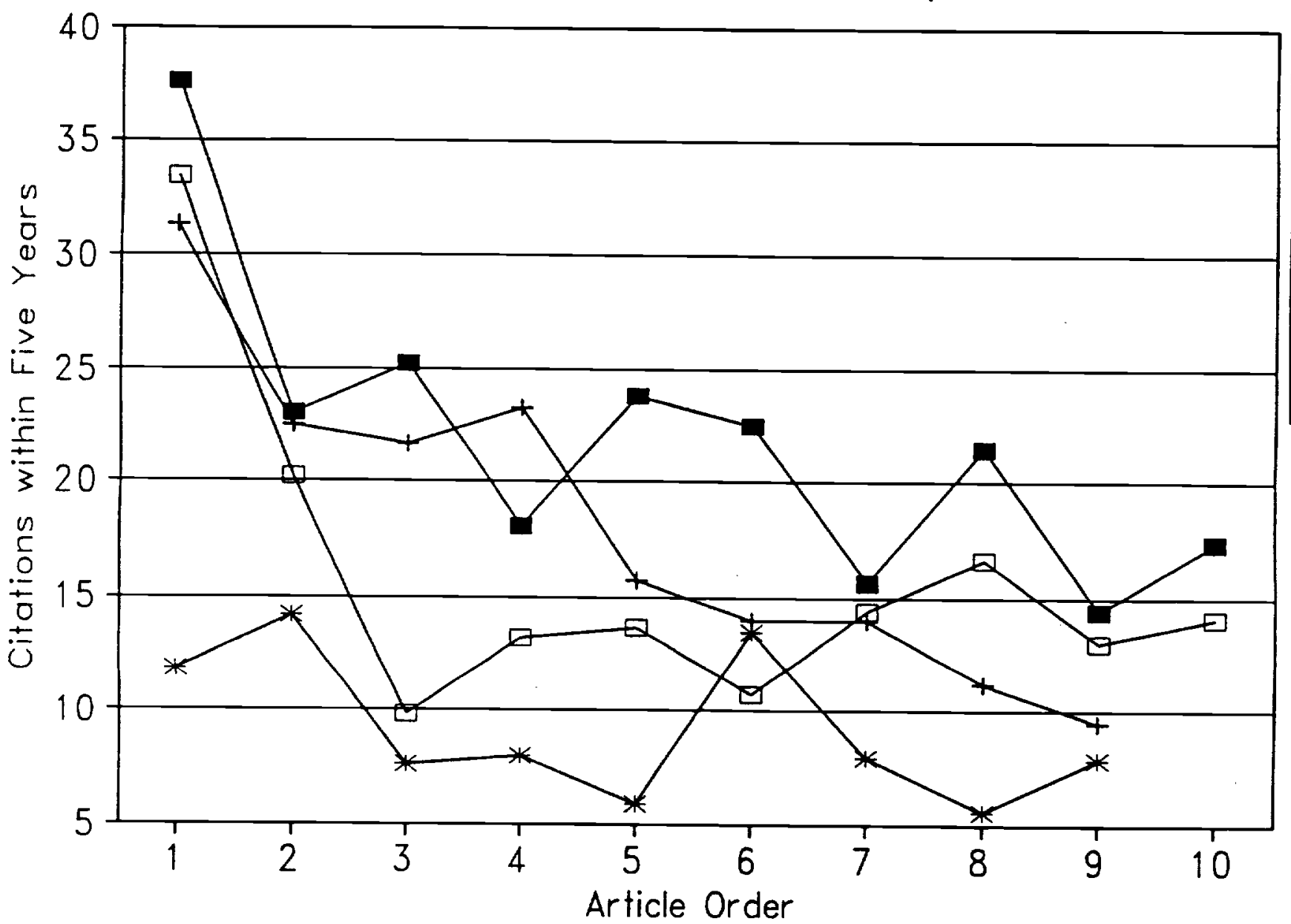

AER
JPE
$\rightarrow *$
QJE
$\square$
ECTA

Note: The figure shows mean citations to articles based on the order in which they appeared in each of four economics journals. The sample includes all full-length articles published from 1980-1985. The lines for the QJE and Econometrica stop at the ninth article order position because these journals do not often publish ten or more articles in a single issue. 


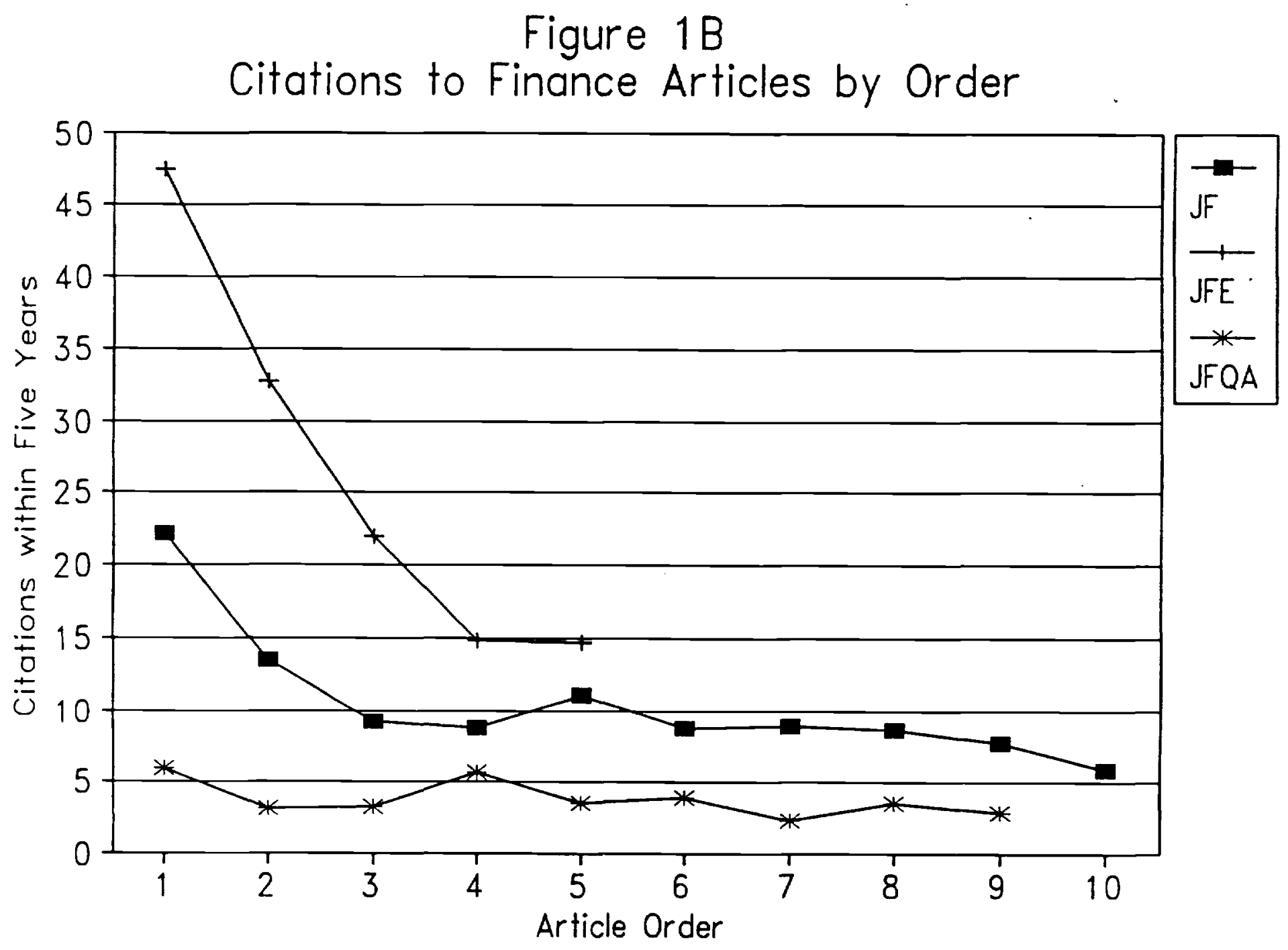

Note: The figure shows mean citations to articles based on the order in which they appeared in each of three finance journals. The sample includes all full-length articles published from 1980-1985. The lines for the JFE and the JFQA stop prior to the tenth article order position because these journals do not often publish ten or more articles in a single issue. 
Figure 2

\section{Citations by Gender and Article Order}

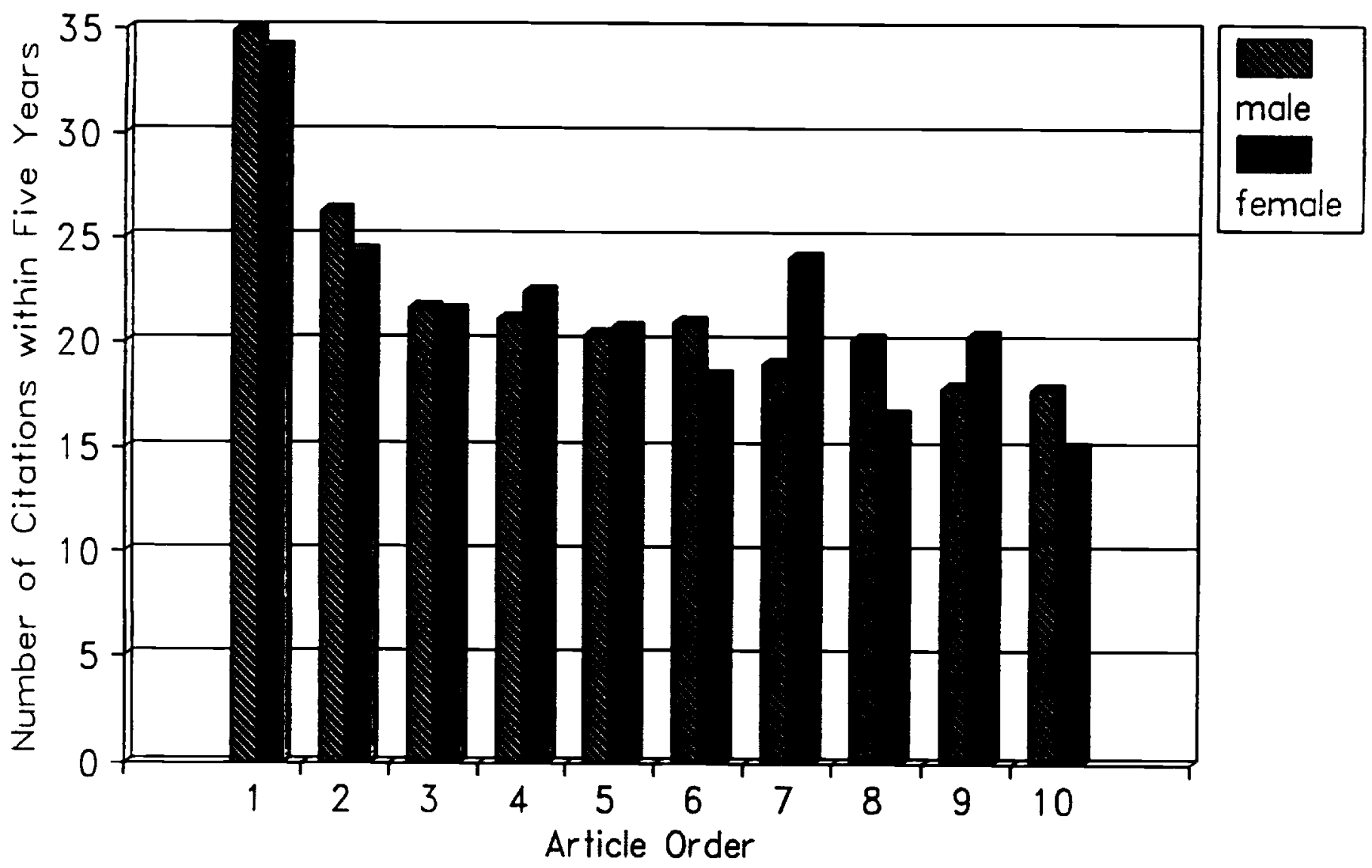

Note: The numbers for this figure are based on a regression of citations within 5 years of publication on journal dummies and the interaction between ten order dummies and an author gender dummy. The pattern in the figure above pertains to the $A E R$. An article is coded as "female-authored" if any author is female. The sample includes all full-length articles published from 1980-1985 in the AER, QJE, Econometrica, JPE, JF, JFE, and JFQA. 


\section{Figure 3 \\ Citations by Ph.D. Vintage and Order}

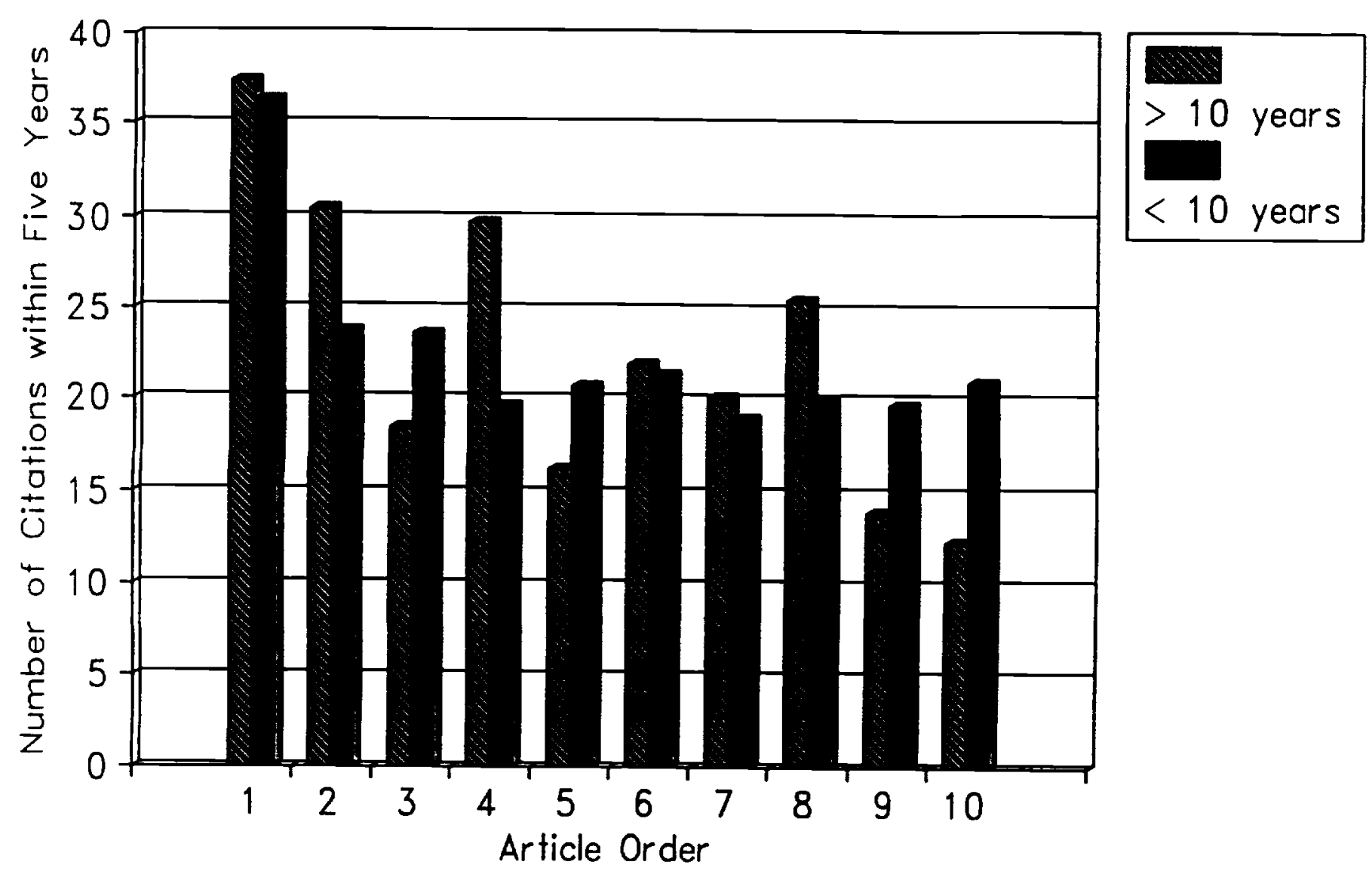

Note: The numbers for this figure are based on a regression of citations within 5 years of publication on journal dummies and the interaction between ten order dummies and a Ph.D. vintage dummy. The pattern in the figure above pertains to the AER. For coauthored papers, the Ph.D. vintage dummy for that article is coded as "greater than 10 years" if any of the authors has held a Ph.D. for at least 10 years. The sample includes all full-length articles published from 1980-1985 in the AER, QJE, Econometrica, JPE, JF, JFE, and JFQA. 
Figure 4

\section{Citations by Field and Article Order}

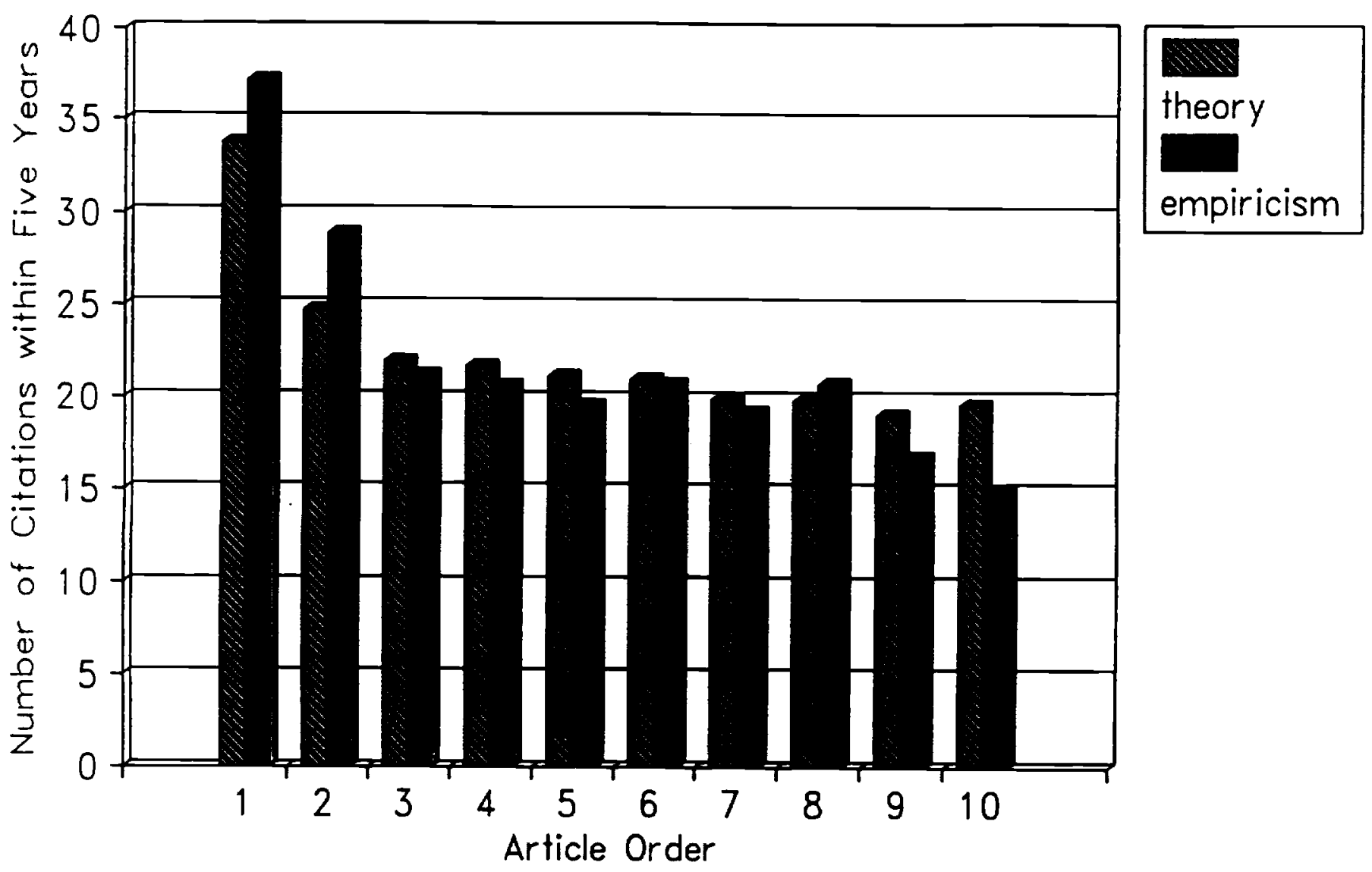

Note: The numbers for this figure are based on a regression of citations within 5 years of publication on journal dummies and the interaction between ten order dummies and field dummy. The pattern in the figure above pertains to the AER. An article is coded as either theory or empiricism based on the first JEL code reported. The sample includes all full-length articles published from 1980-1985 in the AER, QJE, Econometrica, JPE, JF, JFE, and JFQA. 


\section{Figure 5 \\ Citations by Institutional Rank}

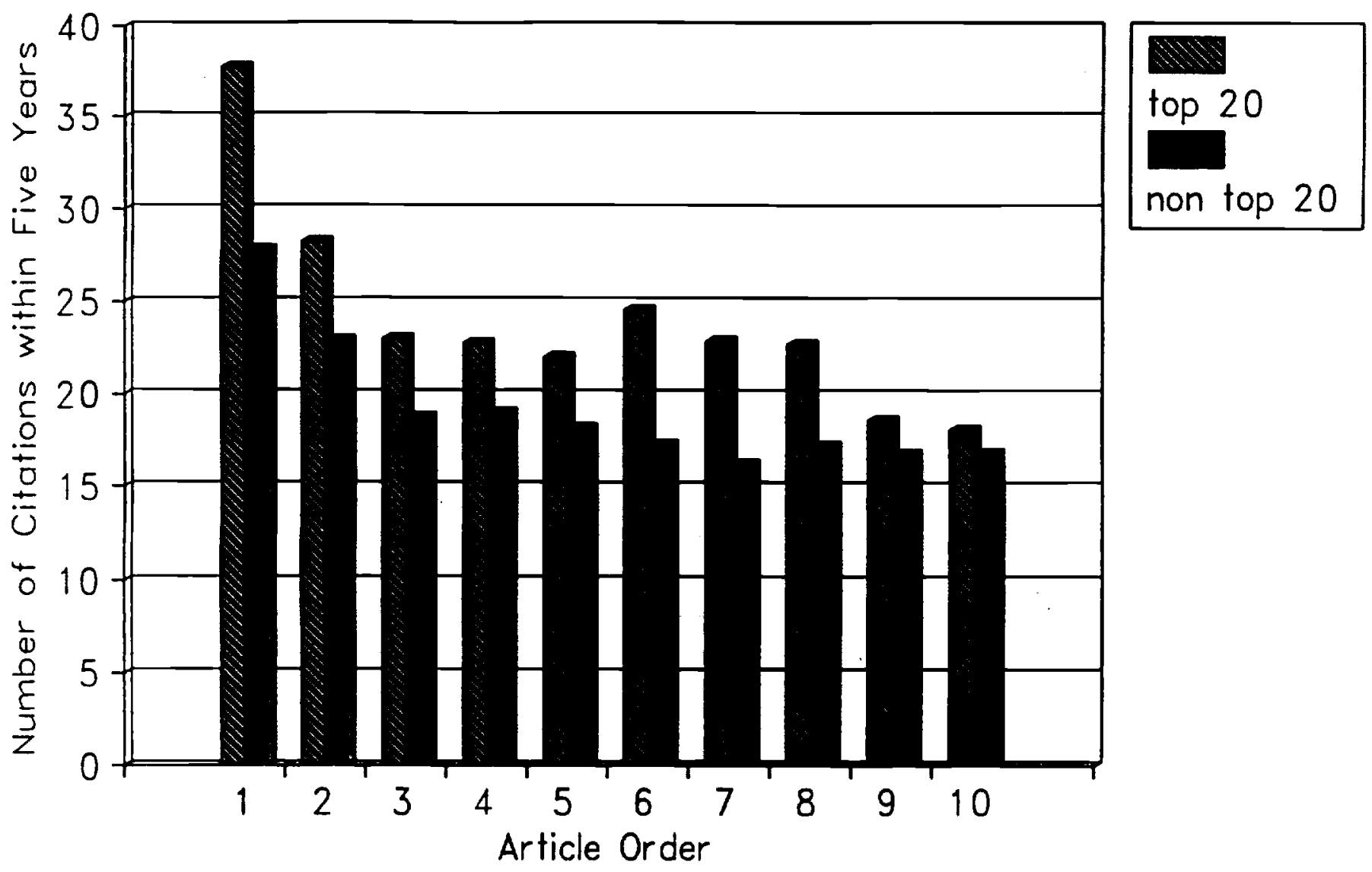

Note: The numbers for this figure are based on a regression of citations within 5 years of publication on journal dummies and the interaction between ten order dummies and an institutional rank dummy. The pattern in the figure above pertains to the AER. For coauthored papers, the institutional rank dummy is coded as "top 20" if any author is from a top 20 department. The sample includes all full-length articles published from 1980-1985 in the AER, $Q J E$, Econometrica, $J P E, J F, J F E$, and $J F Q A$. 


\section{Table 1}

Sample Statistics

Overall AER JPE QJE ECTA JF JFE JFQA

Number of Articles

Citations in Five Years

standard error

Citations in Third to Fifth

Years

standard error

Pages per Article

standard error

Author Gender:

Female

Male

Author Institutional Rank:

Top 5

6 to 20

21 to 50

$51+$

Nonacademic

Foreign

Article Subject:

Theory

Empiricism

Number of Authors:

One

Two

Three +

Time Elapsed between

Ph.D. of Oldest Author

and Publication:

Years

Available Obs.

Articles with Inside

Authors:

Faculty Colleagues

Former Graduate Students

Available Obs.

$\begin{array}{llllllll}1962 & 307 & 309 & 267 & 445 & 284 & 129 & 221\end{array}$

$\begin{array}{llllllll}14.3 & 21.3 & 18.0 & 9.3 & 15.2 & 9.8 & 25.2 & 3.6\end{array}$

$\begin{array}{llllllll}18.9 & 21.0 & 20.3 & 13.8 & 20.1 & 10.5 & 28.5 & 4.1\end{array}$

$\begin{array}{rrrrrrrr}7.5 & 10.6 & 9.5 & 6.1 & 7.6 & 5.3 & 11.2 & 2.4 \\ 8.5 & 9.4 & 8.9 & 10.0 & 8.5 & 4.8 & 8.3 & 2.7\end{array}$

$\begin{array}{llllllll}17.8 & 14.1 & 20.0 & 20.3 & 19.3 & 15.3 & 21.3 & 14.9\end{array}$

$\begin{array}{lrrrrrrr}7.2 & 4.0 & 7.8 & 5.9 & 7.6 & 5.7 & 9.4 & 6.6\end{array}$

$\begin{array}{rrrrrrrr}4.7 \% & 4.2 \% & 3.9 \% & 6.4 \% & 3.8 \% & 5.6 \% & 6.2 \% & 4.5 \% \\ 95.3 \% & 95.8 \% & 96.1 \% & 93.6 \% & 96.2 \% & 94.4 \% & 93.8 \% & 95.5 \%\end{array}$

$\begin{array}{llllllll}22.0 \% & 24.1 \% & 24.6 \% & 23.2 \% & 19.1 \% & 20.4 \% & 43.4 \% & 9.0 \%\end{array}$

$\begin{array}{llllllll}27.0 \% & 29.3 \% & 26.2 \% & 28.1 \% & 29.0 \% & 26.4 \% & 26.4 \% & 20.4 \%\end{array}$

$\begin{array}{llllllll}20.0 \% & 15.6 \% & 23.6 \% & 16.5 \% & 11.9 \% & 26.4 \% & 19.4 \% & 33.9 \%\end{array}$

$\begin{array}{lllllllll}12.7 \% & 15.6 \% & 11.0 \% & 10.9 \% & 7.6 \% & 13.7 \% & 7.0 \% & 25.8 \%\end{array}$

$\begin{array}{llllllll}3.6 \% & 5.9 \% & 3.6 \% & 5.2 \% & 3.1 \% & 3.9 \% & 0.8 \% & 0.9 \%\end{array}$

$\begin{array}{llllllll}13.6 \% & 9.4 \% & 10.4 \% & 16.1 \% & 28.3 \% & 4.6 \% & 3.1 \% & 9.0 \%\end{array}$

$\begin{array}{llllllll}59.7 \% & 53.1 \% & 49.2 \% & 64.4 \% & 88.8 \% & 49.3 \% & 38.0 \% & 45.7 \%\end{array}$

$\begin{array}{llllllll}40.3 \% & 46.9 \% & 50.8 \% & 35.6 \% & 11.2 \% & 50.7 \% & 62.0 \% & 54.3 \%\end{array}$

$\begin{array}{rrrrrrrr}54.5 \% & 58.3 \% & 57.3 \% & 63.3 \% & 58.9 \% & 43.3 \% & 48.1 \% & 43.9 \% \\ 36.6 \% & 32.6 \% & 36.9 \% & 27.3 \% & 33.7 \% & 45.8 \% & 41.9 \% & 44.3 \% \\ 8.9 \% & 9.1 \% & 5.8 \% & 9.4 \% & 7.4 \% & 10.9 \% & 10.1 \% & 11.8 \%\end{array}$

$\begin{array}{llllllll}9.16 & 10.91 & 9.41 & 10.57 & 9.13 & 7.74 & 7.13 & 8.03\end{array}$

$\begin{array}{llllllll}1326 & 213 & 216 & 201 & 209 & 240 & 96 & 151\end{array}$ 
Table 2

\section{Citations and Editorial Treatment}

Dependent Variable: Citations within Five Years

(1)

Constant Terms:

\section{AER}

JPE

ECTA

$\mathrm{JF}$

JFE

JFQA

QJE

Article Order:

1

2

4

5

6

7

8

9

10

$11+$ (omitted)

14.26

5.48

12.52

7.27

19.86

0.28

1.52

0.63

1.33

$-0.85$

$-1.18$
Coef. t-stat Coef.

$18.85 \quad 13.62$

9.09

3.39

9.60

5.28

9.99

0.17

0.34

19.00

11.22

2.88

10.28

6.98

16.19

0.34

(2)

(3)

t-stat Coef. t-stat

\begin{tabular}{l|l}
7.89 & 10.47
\end{tabular}

$4.33 \quad 1.92$

1.05

4.05

2.85

5.78

0.14

$-6.16$

1.61

$-1.52$

6.76

$-8.45$

3.07

0.55

$-1.74$

0.47

$-0.44$

1.85

$-2.52$

\begin{tabular}{ll|ll}
15.83 & 9.27 & 0.40 & 0.11
\end{tabular}

\begin{tabular}{ll|ll}
7.41 & 4.32 & -4.23 & -1.30
\end{tabular}

\begin{tabular}{ll|ll}
2.75 & 1.59 & -7.3 & -2.45
\end{tabular}

\begin{tabular}{ll|ll}
2.37 & 1.37 & -6.15 & -2.27
\end{tabular}

0.89

$-5.37$

$-2.18$

\begin{tabular}{l|ll}
1.07 & -3.74 & -1.64 \\
\hline
\end{tabular}

0.36

$-4.54$

$-2.15$

0.74

$-2.39$

$-0.45$

$-3.72$

$-0.59$

$-3.32$

$-1.19$

$-1.89$

Article Order

Article Order Squared

Pages

Pages Squared

Order*Pages

R-squared

N

1962

0.36

$-0.06$

0.76

0.73

0.31

2.34

0.94

0.22

2.74

0.003

3.52

$-3.41$

$-0.08$

$-4.93$

\begin{tabular}{|c|r|}
\hline 0.20981 & 0.1976 \\
1962 & 1962 \\
\hline
\end{tabular}


Table 3

Bias Results

Dependent Variable: Citations within Five Years

\begin{tabular}{|c|c|c|c|c|c|c|}
\hline \multirow[b]{2}{*}{ Constant } & \multicolumn{2}{|c|}{ (1) OLS } & \multicolumn{2}{|c|}{ (2) OLS } & \multicolumn{2}{|c|}{ (3) Median Regression } \\
\hline & $\begin{array}{l}\text { Coef. } \\
23.33\end{array}$ & $\begin{array}{l}\text { t-stat } \\
12.46\end{array}$ & $\begin{array}{l}\text { Coef. } \\
13.72\end{array}$ & $\begin{array}{l}\text { t-stat } \\
3.87\end{array}$ & \begin{tabular}{|r|} 
Coef. \\
\end{tabular} & $\begin{array}{l}\text { t-stat } \\
13.72\end{array}$ \\
\hline \multicolumn{7}{|c|}{ Journal Dummies (AER excl.): } \\
\hline JPE & -4.35 & -3.09 & -8.09 & -5.78 & -2.00 & -2.39 \\
\hline QJE & -12.84 & -8.79 & -15.89 & -10.88 & -4.67 & -5.96 \\
\hline ECTA & -5.61 & -4.25 & -8.05 & -6.04 & -7.00 & -8.35 \\
\hline JF & -11.92 & -8.43 & -12.26 & -8.84 & 1.33 & 1.21 \\
\hline JFE & -0.31 & -0.17 & -4.65 & -2.53 & -10.67 & -11.72 \\
\hline JFQA & -17.27 & -11.16 & -17.63 & -11.64 & -8.67 & -10.04 \\
\hline \multicolumn{7}{|c|}{$\begin{array}{l}\text { Editorial Treatment Variables: } \\
\text { Article Order }(11+\text { excl.): }\end{array}$} \\
\hline 1 & 13.92 & 8.21 & & & 7.33 & 7.25 \\
\hline 2 & 5.98 & 3.53 & & & 2.33 & 2.33 \\
\hline 3 & 1.42 & 0.83 & & & 0.33 & 0.33 \\
\hline 4 & 1.51 & 0.89 & & & 1.33 & 1.32 \\
\hline 5 & 0.87 & 0.51 & & & 1.33 & 1.31 \\
\hline 6 & 1.23 & 0.72 & & & 1.33 & 1.30 \\
\hline 7 & 0.08 & 0.05 & & & 0.33 & 0.32 \\
\hline 8 & 0.87 & 0.49 & & & 0.67 & 0.63 \\
\hline 9 & -1.80 & -0.97 & & & 0.00 & 0.00 \\
\hline 10 & -1.27 & -0.64 & & & -1.33 & -1.13 \\
\hline Article Order & & & 0.91 & 2.96 & & \\
\hline Order Squared & & & 0.19 & 0.14 & & \\
\hline Pages & & & 0.91 & 3.48 & & \\
\hline Pages Squared & & & 0.00 & 0.58 & & \\
\hline Order*Pages & & & -0.09 & -5.24 & & \\
\hline \multicolumn{7}{|l|}{$\begin{array}{l}\text { Author and Article } \\
\text { Characteristics: }\end{array}$} \\
\hline Female Author & -0.05 & -0.03 & -0.79 & -0.44 & 1.33 & 1.23 \\
\hline \multicolumn{7}{|c|}{ Institution Rank (top 5 excl.): } \\
\hline 6 to 20 & -5.35 & -4.86 & -5.31 & -4.92 & -3.33 & -5.08 \\
\hline 20 to 50 & -7.61 & -6.31 & -7.36 & -6.23 & -5.00 & -6.99 \\
\hline $51+$ & -8.34 & -6.01 & -7.70 & -5.64 & -5.33 & -6.48 \\
\hline Nonac. & -8.74 & -3.97 & -8.27 & -3.84 & -5.00 & -3.85 \\
\hline Foreign & -10.02 & -7.32 & -10.02 & -7.48 & -6.33 & -7.80 \\
\hline Theory & 0.15 & 0.18 & 0.64 & 0.78 & -0.67 & -1.33 \\
\hline Number of Authors & 1.08 & 1.87 & 0.82 & 1.46 & 1.00 & 2.94 \\
\hline $\begin{array}{l}\text { R-sq } \\
\text { Psuedo R-sq }\end{array}$ & 0.1986 & & 0.2293 & & 0.1257 & \\
\hline $\mathbf{N}$ & 1962 & & 1962 & & 1962 & \\
\hline
\end{tabular}


Table 4

Bias Regressions with Journal Interactions

Dependent Variable: Citations within Five Years

\section{Panel A: Editorial Treatment Variables}

\begin{tabular}{|c|c|c|}
\hline Constant Terms: & Coef. & t-stat \\
\hline AER & 36.57 & 9.85 \\
\hline JPE & 30.85 & 8.42 \\
\hline QJE & 16.04 & 3.95 \\
\hline ECTA & 27.63 & 7.79 \\
\hline JF & 22.88 & 6.50 \\
\hline JFE & 63.26 & 11.69 \\
\hline JFQA & 5.75 & 1.48 \\
\hline \multicolumn{3}{|l|}{ AER } \\
\hline Order & -3.38 & -3.00 \\
\hline Order Squared & 0.18 & 2.30 \\
\hline \multicolumn{3}{|l|}{ JPE } \\
\hline Order & -2.59 & -1.81 \\
\hline Order Squared & 0.05 & 0.36 \\
\hline \multicolumn{3}{|l|}{ QJE } \\
\hline Order & -1.71 & -1.09 \\
\hline Order Squared & 0.12 & 0.84 \\
\hline \multicolumn{3}{|l|}{ ECTA } \\
\hline Order & -2.66 & -3.56 \\
\hline Order Squared & 0.13 & 2.74 \\
\hline \multicolumn{3}{|l|}{ JF } \\
\hline Order & -2.10 & -2.38 \\
\hline Order Squared & 0.09 & 1.72 \\
\hline \multicolumn{3}{|l|}{ JFE } \\
\hline Order & -14.49 & -5.10 \\
\hline Order Squared & 1.15 & 3.47 \\
\hline \multicolumn{3}{|l|}{ JFQA } \\
\hline Order & -0.39 & -0.35 \\
\hline Order Squared & 0.01 & 0.14 \\
\hline
\end{tabular}


Table 4 continued

Bias Regressions with Journal Interactions

Dependent Variable: Citations within Five Years

Panel B: Bias Variables

\begin{tabular}{lcc} 
Non-Top 20 & Coef. & t-stat \\
AER & -9.50 & -4.85 \\
JPE & -6.73 & -3.32 \\
QJE & -5.20 & -2.48 \\
ECTA & -6.21 & -3.75 \\
JF & -5.65 & -2.72 \\
JFE & -3.40 & -1.03 \\
JFQA & -0.14 & -0.05 \\
Theory & & \\
AER & & \\
JPE & 2.93 & 1.49 \\
QJE & 3.79 & 1.93 \\
ECTA & 0.29 & 0.13 \\
JF & 0.84 & 0.33 \\
JFE & -2.62 & -1.26 \\
JFQA & -10.31 & -3.30 \\
& -0.65 & -0.28 \\
Female Author & & \\
AER & & \\
JPE & -2.46 & -0.51 \\
QJE & 0.89 & 0.18 \\
ECTA & 3.21 & 0.75 \\
JF & 0.83 & 0.20 \\
JFE & 1.43 & 0.32 \\
JFQA & -8.42 & -1.35 \\
\hline R-squared & 0.31 & 0.06 \\
\hline N & & \\
\hline \hline
\end{tabular}

All estimates in Table 4 are obtained from a regression in which every independent variable (order, order squared, institutional rank dummy, gender dummy, theory dummy) is interacted with each journal dummy. The institutional rank dummy equals one if the author is affiliated with a non-top 20 institution. The theory dummy equals one for theoretical articles, and the female author dummy equals one for articles authored (or coauthored) by women. 
Table 5

Insider Favoritism Regressions by Journal (JPE, QJE, JFE)

Dependent Variable: Citations within Five Years

Constant Terms:

JPE

QJE

JFE

JPE

Article Order

Order Squared

QJE

Article Order

Order Squared

JFE

Article Order

Order Squared

Non-Top 20

JPE

QJE

JFE

Theory

JPE

QJE

JFE

Female Author

JPE

QJE

JFE

Insider Variables:

Faculty Insider

JPE

QJE

JFE
Coef.

26.947

17.997

57.829

$-2.695$

0.071

$-2.677$

0.211

$-9.999$

0.668

$-3.505$

$-4.662$

0.455

4.101

0.566

$-14.804$

4.252

5.870

$-24.996$ t-stat

5.913

3.412

7.762

$-1.542$

0.442

$-1.337$

1.155

$-2.730$

1.586

$-1.357$

$-1.636$

0.098

Ph.D. Insider

JPE

QJE

15.076

3.184

1.100

0.213

29.814

4.031

JFE

4.018

0.712

1.381

$-12.156$

0.208

$-1.828$

R-squared

0.256

N 
Table 6

Longitudinal Estimates of Rank Effect

Years Elapsed

Since Publication

0
1
2
3
4
5
6
7
8
9
10

10
OLS

$\begin{array}{rrrr}\text { Coef. } & \text { t-stat } & \text { Coef. } & \text { t-stat } \\ 2.064 & 6.245 & -2.896 & -14.841 \\ 3.635 & 10.975 & -1.349 & -8.052 \\ 4.815 & 14.505 & -0.184 & -1.100 \\ 5.478 & 16.476 & 0.462 & 2.761 \\ 5.564 & 16.744 & 0.544 & 3.251 \\ 5.547 & 16.679 & 0.527 & 3.143 \\ 5.795 & 16.583 & 0.711 & 3.415 \\ 5.766 & 15.576 & 0.595 & 2.653 \\ 5.632 & 14.062 & 0.514 & 2.091 \\ 5.326 & 11.558 & 0.406 & 1.414 \\ 5.754 & 9.343 & 0.402 & 1.035\end{array}$

Journal Effects

(AER excluded)

$\begin{array}{lll}\text { ECTA } & -0.774 & -3.152 \\ \text { JPE } & -0.137 & -0.551 \\ \text { QJE } & -1.770 & -6.810\end{array}$

Institution Rank

(top 5 excluded)

\begin{tabular}{lrrrr}
6 to 20 & -0.221 & -0.885 & 0.365 & 0.864 \\
21 to 50 & -1.943 & -7.515 & -0.039 & -0.074 \\
$51+$ & -2.248 & -7.028 & -0.136 & -0.227 \\
Nonacademic & -2.275 & -5.441 & -0.850 & -1.177 \\
Foreign & -2.599 & -8.817 & -0.512 & -0.686 \\
\hline $\mathrm{N}$ & 4341 & & 4341 & \\
& & & & \\
R-sq & 0.089 & & 0.109 & \\
\hline
\end{tabular}




\section{References}

Alexander, John C. and Rodney H. Mabry. "Relative Significance of Journals, Authors, and Articles Cited in Financial Research." Journal of Finance 49, no. 2 (June 1994):697-711.

American Economic Association, Journal of Economic Literature, EconLit Database on CDROM. Pittsburgh, PA, 1995.

Ayres, Ian and Joel Waldfogel. "A Market Test for Race Discrimination in Bail Setting." Stanford Law Review 46, no. 5 (May 1994):987-1047.

Becker, Gary S. "Nobel Lecture: The Economic Way of Looking at Things." Journal of Political Economy 101, 385-409.

Blank, Rebecca. "The Effects of Double-Blind versus Single-Blind Reviewing: Experimental Evidence from The American Economic Review." American Economic Review 81, no. 5 (Dec. 1991): 1041-1067.

Borokhovock, Kenneth A., et. al. "Finance Research Productivity and Influence." Journal of Finance, forthcoming (1995).

Ferber, Marianne A. and Michelle Teimann. "Are Women at a Disadvantage in Publishing Journal Articles?" Eastern Economic Journal 6, nos. 3-4 (August-October 1980):189-193.

Ferguson, Michael F. and Stephen R. Peters. "What Constitutes Evidence of Discrimination in Lending?" Journal of Finance, vol. 50, no. 2 (June 1995): 739-748.

Garfunkel, Joseph M., Martin H. Ulshen, Harvey J. Hamrick, and Edward E. Lawson. "Effect of Institutional Prestige on Reviewers' Recommendations and Editorial Decisions." Journal of the Americal Medical Association, vol 272, no. 2 (July 13, 1994): 137-138.

Gilbert, Julie R., Elaine S. Williams, and George D. Lundberg. "Is There Gender Bias in JAMA's Peer Review Process?" Joumal of the Americal Medical Association, vol 272, no. 2 (July 13, 1994): 139-142.

Hasselback, James R. The 1995 Wiley Guide to Finance Faculty New York: Wiley, 1995.

Hellerstein, Judith and David Neumark, "Are Earnings Profiles Steeper than Productivity Profiles? Evidence from Israeli Firm-Level Data." Journal of Human Resources, vol. 30, no. 1 (Winter 1995):89-112.

Jones, Lyle V., Lindzey Gardner, and Porter E. Coggeshall. An Assessment of ResearchDoctorate Programs in the United States: Social and Behavioral Sciences. Report of the Committee on the Assessment of Quality-Related Characteristics of Research-Doctorate Programs in the United States, Conference Board of Associated Research Councils, Washington, DC: National Academy Press, 1982.

Kahn, Lawrence M. "Discrimination in Professional Sports: A Survey of the Literature." Industrial and Labor Relations Review 44, no. 3 (April 1991):395-418.

Laband, David N. and Michael J. Piette, "Favoritism versus Search for Good Papers: Empirical 
Evidence Regarding the Behavior of Journal Editors." Journal of Political Economy 102, no. 1 (1991):194-203.

Leamer, Edward W. "The hit parade of economics articles." Comparative Economics Systems, Exams, Puzzles, and Problems 14, (1981):3-54.

Leibowitz, S. J. and J.P. Palmer, "Assessing the Relative Impact of Economics Journals." Journal of Ecomomic Literature 22 (1984):77-88.

Niemi, Albert W. Jr., "Institutional Contributions to the Leading Finance Journals, 1975-1986: A Note." Journal of Finance 42, 5 (1987): 1389-1397.

Peters, Douglas P. and Stephen J. Ceci. "A Manuscript Masquerade: How Well Does the Review Process Work?" Sciences 20 (1980):16-19.

Schwert, G. William, "The Journal of Financial Economics: A Retrospective Evaluation (197491)." Journal of Financial Economics, 33, (1993): 369-424. 